\title{
RELAÇÕES ENTRE A PROPOSTA DAS CONCEPÇÕES ABERTAS NO ENSINO DA EDUCAÇÃO FÍSICA E O MÉTODO PAULO FREIRE
}

Joaquim Francisco de Lira Neto.

\section{Resumo}

Este trabalho tem o objetivo de identificar possíveis relações entre a proposta das Concepções Abertas no ensino da Educação Física e o método Paulo Freire. A análise das obras deste eminente educador brasileiro proporciona uma melhor compreensão das implicações pedagógicas de determinados pressupostos das Concepções Abertas. São identificadas possíveis convergências entre as duas propostas, como também sérias divergências, que apontam para limitações e problemas da referida proposta de ensino para a Educação Física. A proposta das Concepções Abertas encontra-se sobremaneira presa ao plano das vivências de elementos da cultura corporal; enquanto que a pedagogia de Paulo Freire é capaz de fornecer subsídios para uma proposta que, sem desconsiderar tal plano, enfatize o plano da análise histórica dos referidos elementos, como forma de proporcionar aos alunos uma compreensão sintética das relações entre a cultura corporal e o contexto social mais amplo.

\section{Palavras-Chave:}

Educação Física escolar; Escola ativa; Pedagogia do movimento; Freire, Paulo, 1921-1997; Educação Filosofia.

\section{RELATIONS BETWEEN THE PROPOSAL OF OPEN CONCEPTIONS IN THE PHYSICAL EDUCATION AND THE TEACHING METHOD OF PAULO FREIRE.}

\begin{abstract}
This study aims to identify possible links between the proposal of Open Conceptions in the teaching of Physical Education and the Paulo Freire method. The analysis of the works of eminent Brazilian educator provides a better understanding of the pedagogical implications of certain assumptions of Open Conceptions. Are identified possible similarities between the two proposals, but also serious differences, pointing to limitations and problems of this proposal of Physical Education. The proposal of Open Conceptions is particularly attached to the plane of the experiences of body culture elements, while the Pedagogy of Paulo Freire is able to provide support for a proposal that, without disregard this plan, emphasizes the plan of the historical analysis of this elements as a way to give students an synthetic understanding of the relationship between the body culture and wider social setting.
\end{abstract}

\section{Key-Words:}

School Physical Education; Active school; Pedagogy of the movement, Freire, Paulo, 1921-1997; Education - Philosophy. 


\section{Introdução}

O presente trabalho tem como objetivo identificar possíveis relações entre a proposta das Concepções Abertas no ensino da Educação Física e o método Paulo Freire. Primeiramente, será exposta, em linhas gerais, a primeira das propostas em questão; posteriormente, serão descritas as fases que compõem o método Paulo Freire, para que sejam identificadas as suas possíveis relações com as Concepções Abertas. Além das possíveis convergências entre as duas propostas, serão descritas também as suas possíveis divergências. Finalizando, será feita uma tentativa de se pensar uma aula de Educação Física na perspectiva libertadora de Paulo Freire, que esteja para além dos parâmetros das Concepções Abertas.

É importante ressaltar que a análise aqui empreendida ateve-se aos pressupostos da Pedagogia Libertadora, cujo principal representante é Paulo Freire, por considerar que os mesmos embasam, em parte, a proposta das Concepções Abertas.

O que justifica a elaboração deste trabalho é a possibilidade de se obter um aprofundamento na compreensão das implicações pedagógicas de certos pontos fundamentais da proposta das Concepções Abertas, por meio da pedagogia de Paulo Freire. Tal aprofundamento é necessário porque, sem desconsiderar o alcance de suas contribuições, o conhecimento da Pedagogia Libertadora permite a visualização de problemas e limitações da proposta das Concepções Abertas no ensino da Educação Física.

\section{As Concepções Abertas no Ensino da Educação Física}

A proposta das Concepções Abertas no ensino da Educação Física foi introduzida no Brasil no início da década de 1980 pelos professores Jürgen Dieckert e Reiner Hildebrandt-Stamann. Em um seminário - a partir do qual foi elaborado o livro Pedagogia do movimento: diferentes concepções - o qual contou com a participação do professor Reiner, foi levantada a questão da proximidade entre as Concepções Abertas e a Pedagogia Libertadora. O autor respondeu, então: "algumas reflexões teóricas que eu fiz em relação à experiência tem seu fundo nas reflexões de Paulo Freire" (HILDEBRANDT-STRAMANN, 2004a, p. 72). Entretanto, naquela ocasião esta questão foi apenas sucintamente abordada, dando margem a possíveis questionamentos sobre as relações existentes entre as duas propostas.

Pode-se dizer que a principal preocupação presente na proposta das Concepções Abertas no ensino da Educação Física é a de defender um ensino centrado nos alunos, que considere seus interesses e favoreça 
o papel ativo dos mesmos na relação com os conteúdos. Nesta perspectiva é feita uma crítica ao ensino de movimentos esportivos padronizados que, obedecendo a critérios exclusivamente objetivos, reduz os espaços de elaboração subjetiva dos alunos, que se sentem obrigados a realizar apenas cópias de movimentos estereotipados, assim como a assimilar idéias e valores pertencentes ao sistema do esporte de alto rendimento.

Para Hildebrandt-Stramann (2005, p. 26) o sistema do esporte se caracteriza por duas regras básicas, que são as superiores, quais sejam a "regra do sobrepujar (no sentido de vencer)" e a "regra da comparação objetiva", assim como por "determinados princípios”, que o autor não descreve com exatidão. A primeira regra diz respeito à necessidade característica do sistema esportivo de se chegar em primeiro lugar, o que tem como conseqüência que "o correr, o saltar e o lançar significam percorrer uma distância o mais rápido possível; saltar o mais alto ou o mais longe possível ou, ainda, lançar o mais longe possível" (HILDEBRANDT-STRAMANN, 2005, p. 29). A regra da comparação objetiva refere-se a outro aspecto do sistema esportivo, que é o das medidas objetivas de rendimento, que fazem com que seja necessário “construir instalações análogas para a competição e utilizar os mesmos métodos de verificação do rendimento" (HILDEBRANDT-STRAMANN, 2005, p. 30).

Além disso, apoiando-se em Buytendijk, Hildebrandt-Stramann identifica dois paradigmas distintos na teoria do movimento humano: o paradigma das ciências naturais e o paradigma da reflexão fenomenológica do movimento. Segundo o autor, no primeiro paradigma são diferenciadas as análises morfológica e biomecânica do movimento, que é considerado, em ambas, puramente como o deslocamento de um corpo físico no tempo e no espaço, desconsiderando-se seu aspecto interno. Contrapondo-se a esta visão, o paradigma da reflexão fenomenológica do movimento não analisa movimentos, mas observa homens se movimentando. Nesta visão valoriza-se o aspecto subjetivo do movimento, sua intencionalidade, sua expressividade. Nas palavras de Hildebrandt-Stramann (2005, p. 105): “o movimentar-se sempre está cheio de intenção, sempre é um homem que se movimenta. Esse movimento tem um produto individual e especial".

Enquanto o paradigma das ciências naturais remete a um ensino objetivado, centrado na execução de formas pré-definidas de movimentação, o paradigma da reflexão fenomenológica do movimento, que embasa a proposta das Concepções Abertas, exige uma aula aberta à co-determinação de professor e 
alunos dos objetivos e ações, de maneira a potencializar os espaços de configuração individual dos movimentos que estes realizarão.

Na proposta das Concepções Abertas, a aula é um processo de interação social entre professor e alunos, assim como entre alunos. Tal processo envolve determinadas ações e significados que devem ser construídos conjuntamente - o que é chamado de "co-decisão" (HILDEBRANDT-STRAMANN; LAGING, 1986, p. 11). A co-decisão pode ocorrer segundo diferentes graus de liberdade, sendo que é considera fechada aquela aula em que as decisões quanto ao planejamento e à escolha dos conteúdos assim como ao controle sobre as formas específicas de execução dos mesmos por parte dos alunos - são determinadas unilateralmente pelo professor (HILDEBRANDT-STRAMANN, 2005).

Para romper com a concepção fechada de aulas de Educação Física, elaborou-se a proposta das Concepções Abertas, que é caracterizada da seguinte maneira:

As concepções de ensino são abertas quando os alunos participam das decisões em relação aos objetivos, conteúdos e âmbitos de transmissão ou dentro deste complexo de decisão. O grau de abertura depende do grau de possibilidade de co-decisão. As possibilidades de decisão dos alunos são determinadas cada vez mais pela decisão prévia do professor (HILDEBRANDTSTRAMANN; LAGING, 1986, p. 15).

É importante enfatizar que a proposta das Concepções Abertas não nega a necessidade do planejamento, da escolha dos conteúdos e das intervenções do professor. Há diferentes graus sob os quais ocorre uma aula aberta, mas em nenhum deles os alunos são abandonados exclusivamente à sua livre iniciativa.

Entretanto, embora não esteja completamente ausente, o professor exerce uma ação mediadora no sentido de apenas coordenar as situações de ensino, estimulando a participação dos alunos. Tal ação ocorre através da colocação de "situações-problema ou situações de conflito" (HILDEBRANDT-STRAMANN; LAGING, 1986, p. 21). Assim, os alunos são incentivados a resolver um determinado desafio que requer a construção de movimentos, que - por ser uma situação ampla que permite múltiplas respostas para a sua solução - carregam os significados subjetivos das interpretações fornecidas por cada um dos alunos.

Um dos exemplos de aula fornecidos na obra intitulada Concepções Abertas no ensino da Educação Física tem como tema as "técnicas de arremesso do jogo de handebol" (HILDEBRANDT-STRAMANN; LAGING, 1986, p. 120), sendo que o objetivo da aula é que os alunos reconheçam as diferentes possibilidades de se arremessar em gol. Para a consecução deste objetivo o professor estimula a 
construção, por parte dos alunos, de estações nas quais os mesmos, divididos em grupos, interagem entre si para encontrar diferentes soluções. O professor intervém o menos possível, através de perguntas que problematizam as ações dos alunos.

Os momentos de maior intervenção do professor parecem ser os de reflexões que o mesmo coordena acerca de idéias e valores que permeiam, sobretudo, as práticas esportivas. Sobre a questão da competição, presente não só no esporte mas nas próprias relações capitalistas de produção da economia, Hildebrandt-Stramann (2004a, p. 69-70) afirma que se deve "refletir criticamente que conseqüências sociais têm um aumento, ou simplesmente a participação dentro deste sistema da competição. Participar é refletir sobre as conseqüências sociais que resultam dessa participação". Este aspecto das reflexões nas Concepções Abertas será tratado mais adiante neste trabalho.

Análoga ao que foi dito acima é a defesa de relações democráticas entre professor e alunos. Os alunos devem passar por processos de co-determinação, que contrastam com uma recepção passiva de informações, para aprender a elaborar suas ações de forma mais autônoma. Assim, o aluno "não aprenderá auto e co-determinação, se não houver nada que possa co-determinar. Como poderá adquirir consciência de responsabilidade, se não tiver que arcar com responsabilidade?” (HILDEBRANDTSTRAMANN; LAGING, 1986, p. 11).

Na proposta das Concepções Abertas, a experiência torna-se uma "categoria central na teoria didática das aulas abertas” (HILDEBRANDT-STRAMANN, 2005, p. 79). A experiência vai além da recepção dos dados da realidade até a reformulação dos mesmos pela atividade do sujeito. A questão fundamental aqui é a de que o professor pode prejudicar tal atividade com intervenções excessivas, limitando o espaço de interpretação dos dados objetivos pelos alunos.

Desta forma, na proposta das Concepções Abertas opera-se uma dicotomia entre aulas centradas no professor e aulas centradas nos alunos. Isto fica explícito quando Hildebrandt-Stramann (2005, p. 141) afirma, primeiramente, que: "sob a concepção de aulas fechadas podemos resumir as concepções de aulas orientadas: no professor, no produto; nas metas definidas e na intenção racionalista”. E, posteriormente: "sob a concepção de aulas abertas, podemos resumir as concepções de aulas orientadas: no aluno, no processo, na problematização e na comunicação". 
Após esta breve apresentação da proposta das Concepções Abertas no ensino da Educação Física, procede-se com a descrição das fases que compõem o método Paulo Freire, para que possam ser identificadas as possíveis relações entre as duas propostas.

\section{O método Paulo Freire}

Paulo Freire, um dos maiores pedagogos da história da educação brasileira, começou a desenvolver o seu método no início da década de 1960, no Movimento de Cultura Popular do Recife. Embora tenha sido elaborado no contexto da alfabetização de adultos, o método é, segundo o seu autor, "muito mais uma compreensão dialética da educação do que um método de alfabetização" (FREIRE, 1993, p. 86).

A pedagogia de Paulo Freire, de uma forma geral, preocupa-se com a construção de uma ordem mais democrática na sociedade, o que traz conseqüências para a forma de se pensar a educação. Não somente no Brasil ou no Chile - onde o pedagogo ficou exilado depois do Golpe Militar de 1964 -, a educação deve estar afinada com o interesse maior de contribuir para a transição de uma "sociedade fechada" (FREIRE, 1979, p. 33) para uma sociedade mais aberta, mais democrática.

Segundo o eminente pedagogo brasileiro, a sociedade fechada pode ser caracterizada por possuir "o centro de decisão de sua economia fora dela. Economia, por isso mesmo, comandada por um mercado externo" (FREIRE, 1991, p. 48). Na sociedade fechada há uma elite que governa segundo os interesses da sociedade diretriz, à qual a economia da primeira está subordinada; tal elite impõe uma estrutura social autoritária à classe subalterna. É criada a dicotomia entre trabalho manual e trabalho intelectual e, além disso, os espaços de mobilidade social são extremamente restritos. A questão fundamental aqui é a de que a sociedade fechada elabora um sistema educacional orientado para a manutenção da estrutura social autoritária.

Um dos reflexos da estrutura social fechada na educação refere-se à relação entre professor e alunos. Paulo Freire demonstra forte preocupação com o autoritarismo na prática docente, o que o leva a defender uma relação horizontal entre professor e alunos, que se baseia no diálogo e nutre-se do amor. A referida relação, ao desenvolver a autonomia e a consciência crítica dos alunos, está afinada com a transição para uma sociedade mais democrática. Percebe-se que, de forma semelhante ao que ocorre nas Concepções Abertas no ensino da Educação Física, a pedagogia de Paulo Freire parte do pressuposto de que só se 
aprende democracia por meios democráticos. O autor diz que "se há saber que só se incorpora ao homem experimentalmente, existencialmente, este é o saber democrático" (FREIRE, 1991, p. 92).

Após estas considerações gerais sobre a pedagogia de Paulo Freire, procede-se com a descrição das fases que compõem o seu método, para que, em seguida, sejam identificadas possíveis relações entre ele e a proposta das Concepções Abertas. Como dito anteriormente, o eminente pedagogo elaborou o método voltando-se para a alfabetização de adultos, embora seu alcance esteja muito além do simples aprendizado da leitura e da escrita, como ficará claro a seguir. É importante lembrar que o método teve forte aplicação num espaço institucional específico, o “círculo de cultura” (FREIRE, 1991, p. 103), dirigido para a educação popular, o que não significou a limitação de sua aplicação ao mesmo, sendo possível, talvez com restrições, a sua aplicação na instituição escolar.

A primeira fase do método consiste no levantamento do universo vocabular do grupo popular com que se trabalhará. São feitos encontros de caráter informal com moradores da área em que o método será aplicado, e são escolhidos os "vocábulos mais carregados de sentido existencial e, por isso, de maior conteúdo emocional, mas também fatores típicos do povo" (FREIRE, 1991, p. 112).

A segunda fase consiste na seleção de palavras a partir do universo vocabular levantado. Esta seleção obedece aos seguintes critérios: a) o da riqueza silábica; b) o das dificuldades fonéticas; c) o conteúdo pragmático da palavra, que "implica numa maior pluralidade de engajamento da palavra numa dada realidade social, cultural, política, etc” (FREIRE, 1991, p. 113-114).

É importante ressaltar que Paulo Freire distingue a etapa de alfabetização de uma etapa de pósalfabetização. Enquanto na primeira são escolhidas as palavras, denominadas "geradoras" (FREIRE, 1979, p. 74), na segunda são escolhidos os “temas geradores” (FREIRE, 2005, p. 111). Tanto as palavras como os temas geram não somente um aprendizado da leitura e da escrita, mas, sobretudo, reflexões sobre o contexto em que os educandos estão inseridos. Como diz Brandão (1981, p. 30-31), as palavras geradoras são "instrumentos de releitura coletiva da realidade social onde a língua existe, e existem os homens que a falam e as relações entre os homens". A mesma releitura da realidade é efetuada através dos temas geradores, na etapa de pós-alfabetização. 
A terceira fase consiste na criação de situações existenciais típicas do grupo de educandos com o qual se está trabalhando. Nestas situações são visualizadas as palavras geradoras - na etapa de alfabetização -, assim como os temas geradores - na etapa de pós-alfabetização. Segundo Freire (1991, p. 114), estas situações "funcionam como desafios aos grupos. São situações-problema, codificadas, guardando em si elementos que serão descodificados pelos grupos, com a colaboração do coordenador”.

A codificação das situações existenciais consiste na representação destas, por exemplo, através de fotos ou desenhos, que são apresentados aos educandos para serem descodificados ou seja, para que, através de uma análise crítica, sejam extraídos os significados sociais profundos em filigrana na representação. Um exemplo, que consta em Educação como prática da liberdade, consiste num desenho de um homem próximo a um poço, segurando em uma das mãos um livro e, na outra, uma enxada. Na etapa de alfabetização, por exemplo, poderia ser escolhida a palavra geradora enxada, partindo-se do pressuposto de que aquela situação corresponde ao contexto dos educandos em questão. Na etapa de pósalfabetização, seria feita, por exemplo, uma reflexão sobre as dificuldades objetivas de acesso à cultura erudita.

As duas últimas fases do método dizem respeito mais diretamente à alfabetização. A quarta consiste na elaboração de fichas-roteiro, que auxiliam os coordenadores de debate no seu trabalho com o grupo, enquanto que a quinta consiste na elaboração de fichas com a decomposição das famílias fonéticas correspondentes às palavras geradoras.

Após a descrição de suas fases, um primeiro - e mais geral - aspecto que pode relacionar o método Paulo Freire às Concepções Abertas no ensino da Educação Física é o da ênfase dada ao campo existencial, às experiências já elaboradas pelos educandos no contexto em que vivem.

Paulo Freire defende que os grupos e movimentos populares devem saber melhor o que já sabem; que eles devem se armar "através da organização maior do saber que em seus corpos circula" (FREIRE; NOGUEIRA, 2002, p. 26). Em relação com este aspecto geral compartilhado pelas duas propostas, há um aspecto mais específico das Concepções Abertas, os "blocos de informação" (HILDEBRANDTSTRAMANN; LAGING, 1986, p. 39), que possuem certa analogia com os temas geradores do método Paulo Freire. Os blocos de informação são descritos da seguinte maneira: 
Durante a aula, ou mesmo no início de cada situação de aula, os blocos de informação podem preceder tarefas, temas, questões ou arranjos de aparelhos. O que se pretende dizer é que o professor e / ou os alunos apresentam, com auxílio de demonstrações, descrições ou indicações de movimentos, determinados decursos de movimentos encontrados autonomamente ou regulamentados e jogos. Essas informações formam um tipo de proposta em torno da qual os alunos podem escolher ou desenvolver idéias próprias (HILDEBRANDT-STRAMANN; LAGING, 1986, p. 39).

Apesar das diferenças relativas à especificidade de cada proposta, ambas realizam um levantamento do universo de experiências que os alunos já possuem e que lhes são apresentadas em grupo para serem discutidas, reorganizadas, ampliadas e até mesmo criticadas. Se, no método Paulo Freire, as experiências (universo vocabular) são apresentadas na forma de fotos ou desenhos, na proposta das Concepções Abertas o cabedal de experiências motoras que os alunos possuem lhes é apresentado na forma de demonstrações, descrições ou indicações de movimentos.

Outro ponto comum às duas propostas em questão é o uso de situações-problema para a transmissãoassimilação dos conteúdos. O significado pedagógico da utilização das situações-problema é o favorecimento da atividade dos alunos, o que tem como conseqüência uma certa limitação das intervenções do professor. Aqui as duas propostas começam a divergir e aparecem os problemas e limitações da proposta das Concepções Abertas no ensino da Educação Física.

Como dito anteriormente, há, na proposta das Concepções Abertas, diferentes graus de co-decisão a serem permitidos pelo professor. Contudo, as intervenções do mesmo no momento das vivências de diferentes formas de movimentação, que ocorrem através de sugestões de situações-problema, parecem ser extremamente limitadas. Em certas passagens a ação do professor parece ser considerada até mesmo perniciosa.

Na obra Concepções Abertas no ensino da Educação Física há um espaço destinado a exemplos de aulas ministradas por professores da disciplina em questão que, após reuniões com os autores da obra, "declararam-se prontos a colaborar com os autores neste tipo de ensino aberto em Educação Física" (HILDEBRANDT-STRAMANN; LAGING, 1986, p. 47). Como os exemplos foram escolhidos para compor a obra de modo a ilustrar a proposta dos autores, supõe-se serem fiéis à mesma. Após uma de suas aulas, descritas no livro, o professor Richard Trutti, refletindo sobre seu papel como professor, afirma: 
Nesta aula tive, pela primeira vez, a sensação de ser supérfluo, pelo menos do ponto de vista do papel tradicional de professor. Vista de outra maneira a atividade do professor, não me tornei supérfluo, mas meu trabalho modificou-se qualitativamente. Ele agora se reduz à atividade de aconselhamento em cada técnica de arremesso. A formação organizacional e de conteúdo no âmbito do tema nas estações é assumida exclusivamente pelos alunos. A multiplicidade de variações na execução dos arremessos permite concluir que se trata de uma fantasia viva. Mas ela mostra também como os alunos adaptam as técnicas normatizadas à sua condição subjetiva de saber-fazer. Eu não teria conseguido isso como professor, e com tanta diferenciação! Admiroume, além disso, o jogo final a cujos acontecimentos fiquei completamente alheio. O modo de começar o jogo (sem acordo de regras, sair logo jogando), a experiência da necessidade de regras através de conflitos (em situações de jogo interpretadas subjetivamente de modos diferentes) e a solução através de acordo mostraram, a meu ver, um comportamento tipicamente espontâneo dos alunos fora da escola, que 'normalmente' não chega a aflorar nas aulas (TRUTTI, 1986, p. 124125).

O professor, responsável por ministrar uma aula-exemplo, vangloria-se de ter ficado "completamente alheio" num determinado momento de sua aula; além disso chama a atenção para um comportamento espontâneo dos alunos, que "não chega a aflorar nas aulas", indicando que a intervenção dele neste ponto seria perniciosa, comprometendo a espontaneidade do comportamento.

Outras passagens como esta são encontradas na obra em questão. O problema que aqui pode ser levantado é que os autores da proposta das Concepções Abertas não fazem a reflexão de que, por influência do contexto social, um determinado conteúdo pode requerer uma intervenção do professor que ultrapasse os parâmetros da aula aberta. Por exemplo, é de se duvidar que uma aula de dança, ministrada a alunos de escolas públicas brasileiras, seja construída com uma reduzida intervenção do professor. Isto principalmente no que se refere à participação dos meninos, devido aos preconceitos ainda existentes quanto à prática deste patrimônio da cultura corporal pelo sexo masculino. Quando o conteúdo já agrada aos alunos, o que pressupõe que não rompe com as idéias e valores que os mesmos adquiriram em seu contexto social, é bem possível que o professor possa se ausentar em muitos momentos da aula - como, por exemplo, um professor que queira dar um jogo de futebol em uma aula de Educação Física, no Brasil. Entretanto, quando se trata de romper com um gosto já adquirido e que, como no exemplo dado, carrega preconceitos, a questão torna-se um problema.

O exemplo dado, apesar de banal e de ter sido sobejamente discutido no meio acadêmico da Educação Física, é fundamental para questionar a contradição, operada pelas Concepções Abertas, entre professor e alunos. Ao romper com o preconceito - como no caso supracitado - e favorecer a vivência da dança pelos alunos, o professor, por mais que intervenha, dirija e delimite certos parâmetros de ação dos alunos, estará proporcionando a eles experiências que muitas vezes não adquiririam fora da escola, onde estavam condenados às idéias e valores vigentes. Neste caso, uma intervenção, mesmo que intensa, por parte do 
professor, não representa, num certo sentido, o aprisionamento das subjetividades dos alunos, mas a sua libertação.

Apesar de afirmar a necessidade de se refletir sobre as idéias e valores que permeiam os elementos da cultura corporal, os autores da proposta das Concepções Abertas, por enfatizarem uma intervenção reduzida do professor, comprometem os espaços em que a competência pedagógica do mesmo será exercida. Pode-se levantar a questão de como o professor deveria agir no caso de, na co-decisão dos conteúdos, a maioria dos alunos se opor à dança. Defender a imposição de um conteúdo parece comprometer a subjetivação do ensino; entretanto, sem a dimensão do rompimento com os interesses já adquiridos pelos alunos - que se desenvolvem em relação dialética com as idéias e valores vigentes - é a própria especificidade do ato pedagógico que está comprometida. Este argumento perde o seu valor, evidentemente, quando se defende uma pedagogia da legitimação do existente; uma pedagogia reacionária, de conformação às normas vigentes - o que não parece ser o caso das Concepções Abertas. Para além do problema supracitado, que pertence ao plano da vivência dos elementos da cultura corporal, há ainda as limitações da proposta das Concepções Abertas que pertencem ao plano da análise histórica dos elementos da cultura corporal, o que significa um outro nível na compreensão das relações entre tais elementos e o contexto social mais amplo. Neste ponto são fundamentais as contribuições da Pedagogia Libertadora, de Paulo Freire.

\section{Paulo Freire para além da proposta das Concepções Abertas}

Como dito anteriormente, na proposta das Concepções Abertas, são propostas reflexões sobre idéias e valores que permeiam os conteúdos, sobretudo o esporte. Na referida proposta, além de ser reconhecida a influência do contexto social na constituição da cultura corporal, os valores relacionados, por exemplo, à competição tipicamente capitalista, seriam combatidos. O problema é que, primeiramente, os autores da proposta das Concepções Abertas não reservam um espaço de ação significativo ao professor. Além disso, não descrevem como o esporte e a própria consciência dos alunos são permeados pela visão social de mundo da classe dominante, que legitima a vigência do modo de produção capitalista; como conseqüência, também não indicam as formas concretas pelas quais se daria a superação das condições objetivas as quais correspondem àquelas idéias e valores.

A questão da relação entre consciência e visão social de mundo pode ser respondida, numa análise materialista histórica e dialética, afirmando-se que "a produção de idéias, de representações, da 
consciência, está, de início, diretamente entrelaçada com a atividade material e com o intercâmbio material dos homens, como a linguagem da vida real" (MARX; ENGELS, 1984, p. 36). Paulo Freire, que tem Marx como referência direta em algumas de suas obras, afirma que há uma dialética entre consciência e condições materiais concretas da existência social. Nossa consciência não se constitui de forma independente, assim como não é puro reflexo das relações de produção da economia, embora seja sobremaneira condicionada por elas. Deste condicionamento conclui-se que as idéias da classe dominante “são, em cada época, as idéias dominantes; isto é, a classe que é a força material dominante da sociedade é, ao mesmo tempo, sua força espiritual dominante" (MARX; ENGELS, 1984, p. 72).

A classe dominante pretende dar validade universal às suas idéias e aos seus valores, que, muitas vezes, são indevidamente incorporados pela classe subalterna, pelos oprimidos. Freire $(1980$, p. 58) nos fornece um exemplo de como isto pode ocorrer com o camponês:

É raro o caso de um camponês, promovido a chefe, que não seja mais tirano em relação a seus antigos camaradas que o próprio proprietário. Isto deve-se a que o contexto da situação do camponês permanece sem mudança. Neste exemplo, o chefe, para assegurar seu trabalho, tem de ser tão duro como o proprietário ou ainda mais. Isto ilustra nossa afirmação, segundo a qual, durante a fase inicial da luta, os oprimidos encontram no opressor seu tipo de homem.

Assim como no exemplo do camponês, os alunos chegam à escola com as idéias e os valores da classe dominante, tendo encontrado nos membros da mesma um "tipo de homem” a seguir.

Por não considerar a relação entre consciência e condições materiais concretas da existência social, a proposta das Concepções Abertas também não aponta para a superação de tais condições. A proposta perde-se em considerações que, devido ao seu caráter abstrato, dificilmente levariam os professores de Educação Física a realizar, com seus alunos, análises consistentes e concretas da relação entre os elementos da cultura corporal e o contexto social mais amplo.

Relacionada a isto está a crítica que Sanchs Gamboa (2004, p. 109) faz à proposta das Concepções Abertas, afirmando que a mesma:

Não explicita uma pedagogia voltada para o futuro, não projeta a passagem do passado para o futuro, nem visualiza os caminhos concretos da transformação, embora, em abstrato, se anuncie uma pedagogia libertadora, sem análise crítica das condições concretas passadas e presentes que geram a opressão e a 
exclusão que se localizam nas contradições históricas materiais da sociedade onde a educação é um dos seus componentes.

É importante lembrar que este trabalho busca identificar possíveis relações entre a proposta das Concepções Abertas e o método Paulo Freire, tomando-se como base os pressupostos da Pedagogia Libertadora. A intenção aqui é de fazer uma crítica mais interna que externa a determinados aspectos da proposta das Concepções Abertas.

Desta forma, é importante enfatizar que apesar da forte consideração ao campo existencial, às subjetividades a ao papel ativo dos alunos na relação com os conteúdos, Paulo Freire não deixa de defender a superação das condições objetivas materiais, responsáveis pela vigência das idéias e dos valores que a proposta das Concepções Abertas busca combater em abstrato.

É verdade que Paulo Freire combate determinadas formas perniciosas de intervenção do professor, denominadas por ele de “concepção 'bancária' da educação" (FREIRE, 2005, p. 65), ou "invasão cultural" (FREIRE, 2006a, p. 22); não obstante, ele descreve, em muitas de suas obras, como ocorre a superação dos conhecimentos adquiridos pelos alunos em suas experiências, proporcionada justamente pela ação do professor. Tal ação, partindo do pressuposto da dialética entre consciência e as condições materiais, afirma, junto aos alunos, a necessidade de superação destas. Segundo Freire (1977, p. 13):

Se uma radical transformação das estruturas da sociedade, que explicam a situação objectiva em que se acham os camponeses não se der, eles continuarão os mesmos, explorados da mesma forma, não importa se muitos deles tenham, inclusive, alcançado a razão de ser de sua própria realidade. É que o desvelamento da realidade que não esteja orientado no sentido de uma ação política sobre a mesma, bem definida, clara, não tem sentido.

No método que Paulo Freire defende para a educação ocorre a passagem do abstrato para o concreto, ou seja, das partes ao todo, para que depois se volte às partes sob uma nova compreensão, agora crítica. É o que ocorre no processo de descodificação das situações existenciais anteriormente descrito. Analisando determinados aspectos de sua realidade empírica, os alunos devem se apropriar de instrumentos teóricos que os permitam compreender relações mais profundas presentes na codificação, para que os mesmos aspectos adquiram uma nova compreensão menos ingênua, mais crítica.

Outro aspecto importante da pedagogia de Paulo Freire é o de que, apesar do autor afirmar que "ensinar não é transferir conhecimento, mas criar as possibilidades para a sua produção ou sua construção" (FREIRE, 2006b, p. 22), ele não deixa de reconhecer a "necessidade que temos, educadores e educandos, 
de ler, sempre e seriamente, os clássicos neste ou naquele campo do saber, de nos adentrarmos nos textos, de criar uma disciplina intelectual, sem a qual inviabilizamos a nossa prática enquanto professores e estudantes" (FREIRE, 1995, p. 18).

Isto é fundamental para a pedagogia e, em especial, para a Educação Física porque se refere à especificidade do trabalho escolar, através do qual os alunos entram em contato com o saber elaborado, com os clássicos de uma determinada área do conhecimento. Neste contato é necessária uma certa "disciplina intelectual"; ou seja, as exigências escolares, por lidarem com o saber elaborado, sistematizado, estão além dos esforços intelectuais que os alunos realizam no cotidiano - sobretudo aqueles que pertencem à classe subalterna.

Partindo-se do pressuposto de que sem o saber elaborado os oprimidos encontram-se desarmados frente à classe dominante, e de que a assimilação deste saber requer uma disciplina intelectual, a proposta pedagógica que nega uma certa ruptura com os interesses iniciais que os alunos apresentam é mais reacionária do que revolucionária, estará mais a favor da classe dominante do que do oprimido.

Na Educação Física, o saber elaborado é constituído pelos clássicos da cultura corporal, ou seja, "os jogos, a ginástica, as lutas, as acrobacias, a mímica, o esporte e outros" (SOARES et al., 1992, p. 18). A proposta das Concepções Abertas, além de ter um espaço de acesso aos clássicos comprometido devido ao pressuposto da subjetivação do ensino, está sobremaneira presa ao plano das vivências dos elementos da cultura corporal em detrimento do plano da análise histórica dos mesmos elementos.

Na proposta em questão é defendido que o professor tem dois objetivos: por um lado metas de aprendizagem motora e, por outro, metas de educação no âmbito de valores, normas e virtudes. O importante aqui é que "ambas as metas devem ser alcançadas por meio da atividade física" (DIECKERT, HILDEBRANDT-STRAMANN, 2004, p. 20). Além disso, é bastante significativo que na obra Concepções Abertas no ensino da Educação Física, absolutamente todos os exemplos de aulas sejam de vivências de elementos da cultura corporal.

Desta forma, torna-se compreensível a defesa de um papel reduzido do professor, visto que, além de os conteúdos a serem trabalhados dependerem da co-decisão entre professor e alunos, serão ministrados no plano das vivências, acompanhados apenas por reflexões anexas. Considerando-se o apreço dos alunos 
por aulas em que eles não tenham que fazer muito mais que chutar uma bola, ou arremessá-la numa cesta, as intervenções do professor, de fato, talvez não façam muita falta.

Na perspectiva da Pedagogia Libertadora de Paulo Freire, o saber elaborado deve ser entendido em suas relações com o contexto histórico no qual se constitui. No plano das vivências isto somente é possível num nível elementar. Para além dele, o plano da análise histórica desvela as relações materiais contraditórias que são a base da significação dos elementos da cultura corporal. Esta perspectiva exige um maior esforço intelectual por parte dos alunos, o que é necessário para muni-los de instrumentos teóricos que lhes permitam compreender de forma mais sintética, menos sincrética, as relações entre a cultura corporal e o contexto social mais amplo.

Finalizando este trabalho, numa tentativa de se pensar uma aula de Educação Física na perspectiva libertadora de Paulo Freire, será dado um exemplo de análise histórica de um elemento da cultura corporal. $\mathrm{O}$ elemento escolhido foi o futebol, devido à sua forte presença na cultura brasileira.

Uma aula nesta perspectiva abordaria, por exemplo, o uso ideológico do futebol por parte do Estado no início do século XX, devido ao crescimento da industrialização brasileira.

Segundo Carone (1978), com a Primeira Guerra Mundial a economia brasileira é prejudicada pois era principalmente agrária e voltada para a exportação, atendendo aos interesses imperialistas das potências européias. Com o conflito bélico, o mercado internacional é prejudicado e o Brasil tem sua industrialização impulsionada para atender às necessidades internas.

O crescimento da industrialização foi acompanhado de fortes greves que, como lembra Santos (1981, p. 22), reivindicavam, por exemplo, “oito horas de trabalho, proteção às operárias, melhores salários e condições de higiene nas fábricas”. Neste contexto, o Estado lançou mão do futebol como uma forma de ópio para os grevistas. Nas palavras de Santos (1981, p. 22):

A greve de 1917, que chegou a paralisar dezenas de milhares de operários, fez ver às autoridades e aos industriais que a cidade precisava de um 'esporte de massas'. Como a uma criança que se manda brincar 'para queimar energias', os operários foram, então, mandados jogar futebol: os municípios isentaram os campos de impostos; os industriais se apressaram em construir grounds; a polícia parou de reprimir os rachas em terrenos baldios; os castigos aos estudantes de escolas públicas que fossem pegos jogando futebol, suspensos. 
Tal momento histórico pode ser abordado na escola através de uma ação interdisciplinar entre os professores de História e Educação Física, cada um dentro de sua especificidade. O professor de Educação Física pode tomar a análise acima como exemplo das relações entre os elementos da cultura corporal e as condições materiais concretas da existência social. $O$ ensino que, além do plano das vivências, enfatiza o plano da análise histórica de tais elementos é fundamental - embora menos prazeroso que chutar bolas em gol - para uma compreensão sintética dos alunos sobre as relações entre cultura corporal e o contexto social mais amplo.

\section{Considerações Finais}

Após a descrição de alguns dos aspectos centrais da proposta das Concepções Abertas no ensino da Educação Física, e do método Paulo Freire, é possível que sejam identificadas algumas relações entre as duas propostas. Entretanto, entre elas, como a análise aqui empreendida tentou mostrar, não há somente convergências, mas também sérias divergências. Embora ambas defendam a existência de relações democráticas, horizontais, entre professor e alunos, a pedagogia de Paulo Freire consegue romper com o subjetivismo educacional que perpassa a proposta das Concepções Abertas, constituindo um de seus aspectos centrais.

É importante enfatizar que o que foi proposto aqui como um exemplo de aula de Educação Física na perspectiva da Pedagogia Libertadora teve o intuito de mostrar um ponto que a proposta das Concepções Abertas não atinge. A crítica feita à subjetivação do ensino não defende a execução de movimentos esportivos padronizados, objetivados, que as Concepções Abertas combatem. Defende, primeiramente, uma intervenção mais intensa do professor na qual, exercendo a sua competência pedagógica, ele promove uma certa continuidade, mas, muito além disso, uma certa ruptura, uma superação de parte do cabedal de movimentos, idéias e valores já adquiridos pelos alunos.

Desta forma, contra o que aqui é proposto, não é válida a crítica que Hildebrandt-Stramann (2004b) faz à abordagem crítico-superadora da Educação Física - abordagem que se aproxima da aqui defendida pelas referências que faz a Marx, e que também são feitas por Paulo Freire, embora o autor não seja considerado, propriamente, um marxista. $\mathrm{O}$ autor das Concepções Abertas afirma que a estrutura teórica da abordagem crítico-superadora "não aponta para uma prática que se distinga do conceito dos tipos de esporte hegemônico. Pelo contrário, freqüentemente a estrutura teórica encobre essa prática, figurando, assim, como ideologia" (HILDEBRANDT-STRAMANN, 2004b, p. 39). 
Para além do plano das vivências dos elementos da cultura corporal, a crítica da subjetivação do ensino alcança o plano da análise histórica dos mesmos elementos. A proposta das Concepções Abertas está sobremaneira presa ao plano das vivências, acompanhadas de reflexões anexas. O que se propõe aqui é um planejamento de aulas de Educação Física que, não deixando de reservar um espaço para as vivências, reserve um amplo espaço para as aulas destinadas a análises históricas dos elementos da cultura corporal; aulas em sala, com leituras de textos que proporcionem a disciplina intelectual necessária para uma compreensão mais aprofundada das relações entre cultura corporal e as contraditórias condições materiais da existência social.

Este tipo de planejamento aqui defendido em substituição ao planejamento de aulas em que os alunos somente vivenciam práticas que inclusive eles mesmos ajudaram a escolher, possivelmente será rejeitado pela maioria do corpo discente. Criar uma disciplina intelectual, desenvolver o gosto pela leitura do saber elaborado em qualquer área do conhecimento, não é um processo fácil; requer uma certa ruptura, sem a qual os alunos estão condenados aos fáceis prazeres nos quais predominam os interesses da classe dominante. É necessário optar pela preservação e legitimação do existencial colonizado, através de uma pedagogia reacionária, ou, ao contrário, optar por uma certa ruptura, por uma superação das idéias e valores vigentes, através de uma pedagogia libertadora, verdadeiramente revolucionária.

\section{Referências}

BRANDÃO, C. R. O que é método Paulo Freire. 2 ed. São Paulo: Brasiliense, 1981.

CARONE, E. A República velha: instituições e classes sociais (1889 - 1930). 4. ed. São Paulo: Difel, 1978. v. 1 .

DIECKERT, J.; HILDEBRANDT-STRAMANN, R. Perspectivas para o desenvolvimento da ciência do esporte no Brasil com enfoque na formação de professores de Educação Física escolar - ponto de vista 
alemão. In: KUNZ, E.; HILDEBRANDT-STRAMANN, R. (Org.). Intercâmbios científicos internacionais em Educação Física e esportes. Ijuí: Ed. Unijuí, 2004.

FREIRE, P. Educação política e conscientização. 2 ed. Lisboa: Sá da Costa Editora, 1977. . Educação e mudança. Rio de Janeiro: Paz e Terra, 1979.

- Conscientização: teoria e prática da libertação: uma introdução ao pensamento de Paulo Freire.

3 ed. São Paulo: Moraes, 1980.

. Educação como prática da liberdade. 20 ed. Rio de Janeiro: Paz e Terra, 1991. . Política e educação: ensaios. São Paulo: Cortez, 1993. . A importância do ato de ler: em três artigos que se completam. 31 ed. São Paulo: Cortez, 1995. . Pedagogia do oprimido. 44 ed. Rio de Janeiro: Paz e Terra, 2005. . Extensão ou comunicação? 13. ed. Rio de Janeiro: Paz e Terra, 2006a. . Pedagogia da autonomia: saberes necessários à prática educativa. 34. ed. São Paulo: Paz e Terra, 2006b.

FREIRE, P.; NOGUEIRA, A. Que fazer: teoria e prática em educação popular. 7 ed. Petrópolis, Rio Janeiro: Vozes, 2002.

HILDEBRANDT-STRAMANN, R. Debate. In: CHAVES, M. (Org). Pedagogia do movimento: diferentes concepções. Maceió: EDUFAL, 2004a.

- Perspectivas para a continuação do desenvolvimento da ciência do esporte no Brasil, com enfoque na formação de professores de Educação Física: uma introdução ao tema do simpósio. In: KUNZ, E.; HILDEBRANDT-STRAMANN, R. (Orgs.). Intercâmbios cientificos internacionais em Educação Física e esportes. Ijuí: Ed. Unijuí, 2004b.

. O esporte como fenômeno social e a análise crítica do esporte. In: HILDEBRANDTSTRAMANN, R. Textos pedagógicos sobre o ensino da Educação Física. 3 ed. Ijuí: Ed. Unijuí, 2005.

. Visão pedagógica do movimento. In: HILDEBRANDT-STRAMANN, R. Textos pedagógicos sobre o ensino da Educação Física. 3. ed. Ijuí: Ed. Unijuí, 2005.

. Configuração pedagógica do movimento esportivo no ensino de aulas de Educação Física. In: HILDEBRANDT-STRAMANN, R. Textos pedagógicos sobre o ensino da Educação Física. 3. ed. Ijuí: Ed. Unijuí, 2005.

SANCHES GAMBOA, S. S. Retomando o debate sobre a pedagogia do movimento. In: CHAVES, M. (Org.). Pedagogia do movimento: diferentes concepções. Maceió: EDUFAL, 2004.

SOARES, C. L. et al. Metodologia do ensino da Educação Física. São Paulo: Cortez, 1992. 
STRAMANN, R. Experiência: uma categoria central na teoria didática das aulas abertas. In: HILDEBRANDT-STRAMANN, R. Textos pedagógicos sobre o ensino da Educação Física. 3. ed. Ijuí: Ed. Unijuí, 2005.

. Reflexões pedagógicas sobre a relação entre educação, esporte e a aula de Educação Física. In: HILDEBRANDT-STRAMANN, R. Textos pedagógicos sobre o ensino da Educação Física. 3. ed. Ijuí: Ed. Unijuí, 2005.

HILDEBRANDT-STRAMANN, R.; LAGING, R. Concepções abertas no ensino da Educação Física. Rio de Janeiro: Ao Livro Técnico, 1986.

MARX, K.; ENGELS, F. A ideologia alemã: Feuerbach. 4. ed. São Paulo: Hucitec, 1984.

SANTOS, J. R. História política do futebol brasileiro. São Paulo: Brasiliense, 1981.

TRUTTI, R. Série de aulas: saltar e handebol. In: HILDEBRANDT-STRAMANN, R.; LAGING, R. Concepções Abertas no ensino da Educação Física. Rio de Janeiro: Ao Livro Técnico, 1986. 
Joaquim Francisco de Lira Neto

Faculdade de Educação/Unicamp

Email jocalira@hotmail.com

Data de recebimento:

Data de aceite: 